\title{
The Effect of OFDI Reverse Technology Spillovers from ASEAN on China's Economic Growth
}

\author{
CHEN Xianfeng ${ }^{1, a}$, LI Yan ${ }^{2, b}$ \\ ${ }^{1}$ School of Management and Economics,Beijing institute of technology,Beijing 100081, China; \\ ${ }^{2}$ School of Public Policy and Management,Tsinghua University,Beijing 100084, China
}

Keywords:outward foreign direct investment (OFDI); reverse technology spillovers (RTS); Association of Southeast Asian Nations (ASEAN)

\begin{abstract}
Based on the panel data of Chinese outward foreign direct investment(OFDI) to 26 Association of Southeast Asian Nations(ASEAN)countries from 2003 to 2010,Using Integration, error correction model, impulse response function and the GLS method,this paper analyzes the effect of OFDI reverse technology spillovers(RTS) from the ASEAN on China's economic growth,and finds:(1)whether from short-term or long-term perspective,the role of RTS on promoting China's economic growth is proved,but the effect size is less than FDI;(2)The FDI from ASEAN can promote China's OFDI to ASEAN countries, however the OFDI cannot significantly promote FDI to increase;(3)In the long run, the effect gap between OFDI and FDI is narrowing, especiallyafter the economic crisis this trend is more obvious;(4) Developed countries have a greater impact on China's economy than developing countries.
\end{abstract}

\section{Introduction}

To get OFDI reverse overflow is a very important reasonfor China's foreign direct investment (GAO Wen Ling 2012).In other words, through foreign direct investment, multinational enterprises can be close to the state-of-the-art R \& D resources in host country, and then get technology spillover from the host country to the home country, this kind of effect is called reverse spillovers.

Duning (1994) ${ }^{[1],}$ Brunovan Pottelset al (2011) ${ }^{[2]}$, Nigel Driffield \& James HLove (2009, 2012) ${ }^{[3][4]}$, Zouyu Juan (2012) ${ }^{[5]}$, Yin et al $(2013)^{[6]}$, all did a special study about this from different perspectives.

However, the above research isonly about the impacts of the OFDI on China's trade (including import and export)or GDP, on the one hand, does not distinguish between the unique role of the different economies, on the other hand, directly using OFDI data cannot reflect the size of the reverse technology spillovers. In this paper, We first use the OFDI reverse technology spillover model corrected from BK model to measure ASEAN's OFDI reverse overflow size, and then test the impact of this reverse overflow on short-term and long-term economic growth in China, and finally give policy recommendations.

\section{OFDI Reverse Technology Spillover Correction Model}

The modified reverse technology spillover model used in this article is based on the BK (Bitzer \& Kerekes, 2008) model, as shown in Figure 1: 


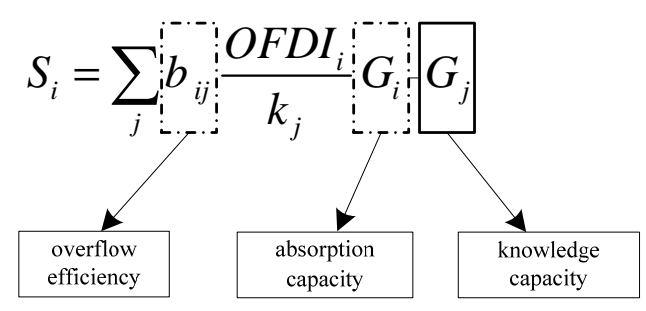

Figure 1. OFDI reverse technology Spillover model

Which ${ } F D I_{i}$ is the foreign direct investment stock of an investment country; ${ }^{k_{j}}$ isthe investment

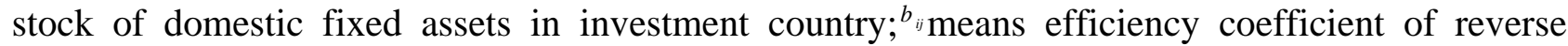
technology overflow which is introduced in the dashed box, and measured by "bilateral trade volume" and "technology distance" between and of the two countries; $G_{i}$ is the home country's absorption capacity; ${ }^{j}$ is the knowledge ability of the host country which is calculated by energy exports, number of scientific papers, patent applications and the high-tech exports of the host country.

\section{Model Specification and Data Selection}

Consider the logarithmic form of extended Cobb-Douglas production function to measure the impact of FDI and OFDI technology spillover on economic growth, as follows:

$$
\ln Y_{i t}=\beta+\beta \ln K_{i t}+\beta_{2} \ln L_{i t}+\beta_{3} F D_{i t}+\beta_{4} O F D_{i t}+\beta_{5} \ln X_{i t}+\varepsilon_{i t}
$$

Among them:

1) Y represents output, measured by annual real GDP (billion) ,adjusted to 2000 constant prices;

2) L means labor level, using the "employed persons in urban and rural areas (tend of the year)" indicatorin China Statistical Yearbook ,million units;

3)K is fixed capital stock, measured by the sustainable archiving method, seeing (2).

$$
K_{i t}=I_{i t}+(1-\eta) K_{i, t-1}(2)
$$

Which $I$ is annual investment, adjusted to 2000 constant prices; ${ }^{\eta}$ is the depreciation rate, setting at $9.6 \%$.

4)FDI: china received the direct investment flows from the respective countries, units of ten thousand U.S. dollars.5)OFDI: the OFDI reverse technology spillover effect size calculated in accordance with the above amendment model;What's more, China's imports are set to the control variables and dummy variables are constructed to reflect the type of the host economy, such as the developed countries are set to 1 , and 0 otherwise.

\section{Empirical test of ASEAN}

First make sure the data through variable unit root test, and granger causality analysis also proved that there is a strong causal relationship between variables, then measure the specific coefficient of the variables by regression analysis.

\section{A.Error correction model and the GLS model}

First to generate first order difference of the variables using Eviews software, and then to do regression analysis, the error correction model meaning short-term effects can be established:

$$
\begin{aligned}
\Delta \ln G D P= & 0.801 \Delta \ln K+0.296 \Delta \ln L+0.165 \Delta \ln F D I+0.041 \Delta \ln \text { OFDI } \\
t= & (4.922) \quad(4.669) \quad(1.984) \\
+ & 0.290 \Delta \ln X-0.537 u-0.001 \\
& (21.423) \quad(14.254) \quad(14.864) \\
& R^{2}=0.999, \quad \bar{R}^{2}=0.999, \quad F=56.97,
\end{aligned}
$$


The regression coefficients passed the significancetestand the coefficient of error correction term $\mathrm{u}$ is negative,which is in line with the reverse correction mechanism.

Meanwhile, the results show that the impact of OFDI reverse technology spillover on short-term growth is positive, but less than the role of FDI $(0.041<0.165)$, which means it takes time for the role of OFDIto catch up with the role of FDI.

Error correction model reflects a short-term relationship between the variables, the long-term effectiveness of variables is measured by GLS (Generalized Least Squares) method, and the results are as follows:

Table 1. GLS estimation results of ASEAN countries

\begin{tabular}{|c|c|c|}
\hline & Fixed effect $^{\mathrm{a}}$ & Random effect \\
\hline & $\ln G D P$ & $\ln G D P$ \\
\hline $\operatorname{lnK}$ & $\begin{array}{c}0.952 * * * \\
(0.0389)\end{array}$ & $\begin{array}{c}0.952 * * * \\
(0.0373)\end{array}$ \\
\hline $\ln \mathrm{L}$ & $\begin{array}{c}0.7228 * * * \\
(1.099)\end{array}$ & $\begin{array}{c}0.7195^{* * *} \\
(1.052) \\
\end{array}$ \\
\hline $\operatorname{lnFDI}$ & $\begin{array}{c}0.1668 * * \\
(0.003)\end{array}$ & $\begin{array}{c}0.0933 * \\
(0.00118) \\
\end{array}$ \\
\hline $\operatorname{lnOFDI}$ & $\begin{array}{c}0.0523^{* *} \\
(0.0284)\end{array}$ & $\begin{array}{c}0.0214^{*} \\
(0.000454)\end{array}$ \\
\hline $\ln X$ & $\begin{array}{c}0.298 * * * \\
(0.256)\end{array}$ & $\begin{array}{c}0.310^{* * *} \\
(0.0225)\end{array}$ \\
\hline Cons & $\begin{array}{c}77.68^{* * *} \\
(11.57)\end{array}$ & $\begin{array}{c}77.08 * * * \\
(11.04)\end{array}$ \\
\hline $\mathrm{N}$ & 72 & 72 \\
\hline adj. R2 & 0.998 & 0.964 \\
\hline Hausman & & \\
\hline
\end{tabular}

a. According to the hausman test, the model is more accurate.

According to the hausman test, we use the fixed effects model to analyze the result.It can be found, the long-term effects of $\operatorname{lnK}$ and $\mathrm{lnL}$ on ecomomic growth are higher than the short-term effects of them $(\operatorname{lnK}: 0.952>0.801 ; \operatorname{lnL}: 0.7228>0.296)$, and the results are significant.

There is a little difference between the the short-term and long-term role of lnOFDIand lnX (import) on economic growth,although the long-term effectsare slightly higher than their short-term effects, but both the gap are less than 0.01 (FDI: 1668> 0.165; import: 0.298>0.290). The elastic of FDI floats up and down in the 0.166 level, and the role of imports is at 0.295 level. The long-term role of OFDI is also higher than the short-term effect.

The same as the short-term effect, the role of OFDI in the long-term is still smaller than FDI, but as time goes on, the gap between the two narrowed to $0.1145(0.1668-0.0523=0.1145)$ from $0.124(0.165-0.041=0.124)$. This also shows with China's OFDI to ASEAN countries continue to grow,the role of OFDI will be increasingly strong.

B. Impulse response function

The above analysis areabout theshort-term and long-term static effects of overflow and reverse technology,in the following,using the VAR model and the corresponding impulse response function to test the short-term dynamic process.

Afterthrough root mold inspection, pulse responsesare shown below: 

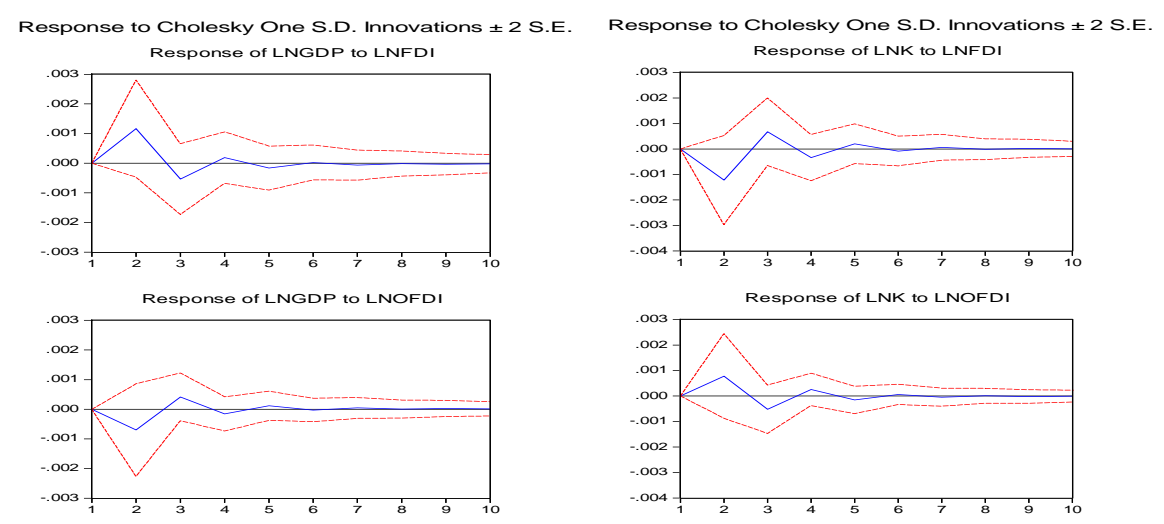

Figure 2.The impulse response function of $\operatorname{lnGDP} \& \operatorname{lnK}$ to $\operatorname{lnOFDI}$

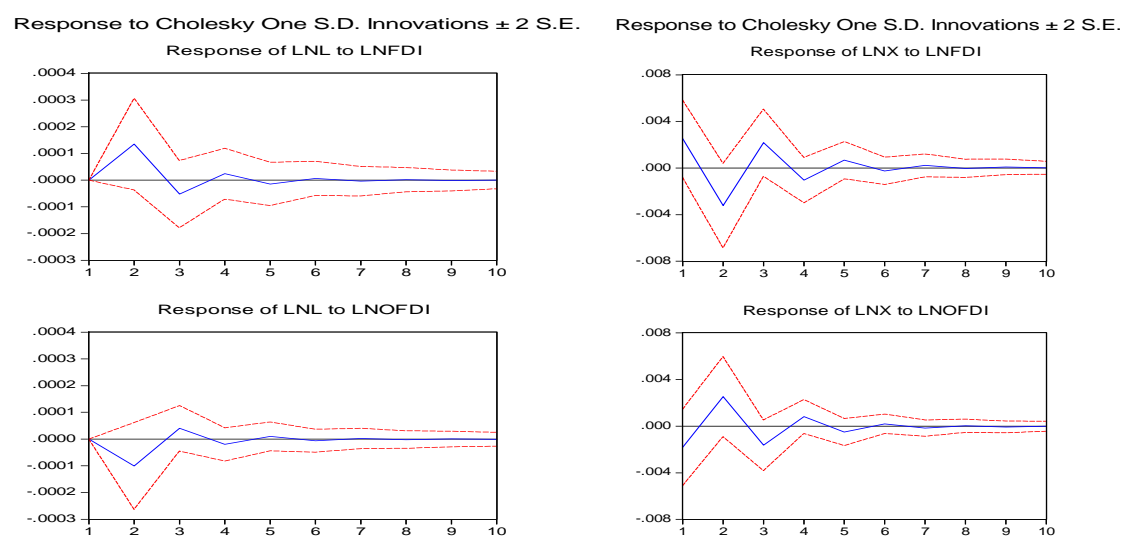

Figure3.The impulse response function of $\ln L \& \ln X$ to $\ln O F D I$

From Figure 2 and Figure 3, for the impact of $\operatorname{lnFDI}$, the responses of $\operatorname{lnGDP}$ and $\ln L$ are similar which generally are positive effects. In the meanwhile, $\ln K$ and $\ln X$ also show similar performance and the $\ln \mathrm{X}$ is more sensitive.Both of them have minor but positive response.

For the impact of lnOFDI, the performance of $\operatorname{lnGDPand} \ln L$ are very similar. But on the contrary tolnFDI, both the two first appeared negative impact, and then 3 forward, only just representspositive response. And the performance of $\operatorname{lnK}$ andlnX is also similar, just the $\operatorname{lnK}$ risesfrom the 0 level and $\ln X$ risesfrom negative valueand ultimately on the whole, the two effects are positive.

C.The impact of the economic crisis

In order to analyze the changes of OFDI reverse technology overflow from ASEAN before and after the economic crisis, the data is divided into 2003-2007 and 2008-2010, the results of two sets are shown in Table 2.

Table2. changes of reverse technology spillover from ASEAN before and after the economic crisis

\begin{tabular}{|l|l|l|l|l|}
\hline & \multicolumn{2}{|l|}{$2003-2007$} & $2008-2010$ & \\
\hline & Fixed effect & Random effecta & Fixed effecta & Random effect \\
\hline & lnGDP & lnGDP & lnGDP & lnGDP \\
\hline $\ln L$ & 0.523 & $0.648^{* * *}$ & $0.571^{* * *}$ & $0.481^{* * *}$ \\
& $(0.542)$ & $(0.383)$ & $(0.283)$ & $(0.183)$ \\
\hline $\ln \mathrm{N}$ & $0.401^{* * *}$ & $0.414^{* * *}$ & $0.551^{* * *}$ & $0.456^{* * *}$ \\
& $(0.0554)$ & $(0.0491)$ & $(0.213)$ & $(0.321)$ \\
\hline $\ln$ FDI & 0.1199 & $0.2094^{* * *}$ & $0.1242^{* * *}$ & $0.1078^{* * *}$ \\
& $(0.0169)$ & $(0.0654)$ & $(0.013)$ & $(0.043)$ \\
\hline $\ln$ OFDI & 0.0336 & $0.0710^{* * *}$ & $0.0336^{* * *}$ & $0.0228^{* * *}$ \\
& $(0.0191)$ & $(0.0242)$ & $(0.0013)$ & $(0.0042)$ \\
\hline
\end{tabular}




\begin{tabular}{|l|l|l|l|l|}
\hline $\ln \mathrm{X}$ & $0.342^{* * *}$ & $0.347^{* * *}$ & 0.255 & 0.213 \\
& $(0.0461)$ & $(0.0418)$ & $(0.1418)$ & $(0.1634)$ \\
\hline Dev & $0.0021^{* * *}$ & $0.0024^{* * *}$ & $0.0022^{* * *}$ & $0.0016^{* * *}$ \\
& $(0.0022)$ & $(0.0042)$ & $(0.0011)$ & $(0.0012)$ \\
\hline Cons & 5.641 & 6.874 & 4.330 & 4.330 \\
& $(16.25)$ & $(14.55)$ & $(6.112)$ & $(5.446)$ \\
\hline $\mathrm{N}$ & 45 & 45 & 27 & 27 \\
\hline adj. R2 & 0.999 & 0.995 & 0.966 & 0.945 \\
\hline
\end{tabular}

a. According to the hausman test, the model is more accurate.

According to the hausman test, we use the random-effects model to analyze the 2003-2007 results and use fixed effect model to analyze the 2008-2010 results. It can be found, after the crisis the elastic of $\operatorname{lnK}$ reduced 0.077 , a decline of $11.88 \%$.On the contrary, theelastic of $\ln L$ increased 0.137, an increase of 33.09\%.

As far as lnFDI and lnOFDI be concerned, theelasticity of lnFDI decreased 0.0852 , a decrease of $40.68 \%$.The role of lnOFDI also fell, dropping $52.67 \%$.The difference between them is down to 0.0906 after crisis from 0.1384 before crisis.

What's more,the coefficient of dummy variable Dev is positive and significantly at $1 \%$ level, thus, we believe that the developed countries from ASEAN in promoting China's economic than developing countries have an advantage.

\section{Policy Proposal}

A.Pay more attention on investment in developed countries

Now most of the China's foreign direct investmentflows to other developing countries, but according to the results from our study, the reverse technology spillover from developed countries plays more important role on China's economic growth, so it should focus on investment in developed countries.

B.Take positive and effective measures for the different policies of the host country

The reaction of host countries who receive foreign direct investment is mixed. Some countries welcome more foreign direct investment from other economies, looking on it as one of the new sources of capital and knowledge; however some countries regard it as a new competition. They introduce different policies and the government of China should take positive and effective measures for the different policies of the host country

C.Increase the support for enterprises

There is a need to strengthen the economic role of the government to provide a full range of support and services, to promote the development of enterprises.

D.Take a long-term benefits view

From the impulse response function above, the impacts of OFDI on GDP and labor are negative in the short term, turning positive only after two years, but in the long run has a positive role. This shows that we need to look at the long-term interests of OFDI and make it do more contributions to China's economic growth and scientific and technologicalprogress.

\section{References}

[1]Dunning, J. H., “Multinational Enterprises and the Globalization of Inventory Capacity,” Research Policy, vol.23, pp. 67-88, 1994.

[2]Lichtenberg, B. V. P. d. l. P. a. F., "Dose Foreign Direct Investment Transfer Technology across Borders,” The Review of Economics and Statistics, vol. 83,pp. 490-497,2011.

[3]Love, N. D. a. J. H., "Foreign Direct Investment, Technology Sourcing and Reverse Spillovers," The Manchester School, vol.71, pp.659-672,2009. 
[4]Love, N. D. a. J. H., "Linking FDI Motivation and Host Economy Productivity Effects:

Conceptual and Empirical Analysis,” Journal of International Business Studies, vol.

38,pp.460-473,2012.

[5]Yujuan Zou, "Foreign direct investment in developing countries, the reverse technology transfer and technological upgrading of the home country,” Economic Issues, vol.4, pp.105-108,2012.

[6]Yin Hua,etl. "Technology seeking Enterprise through OFDI in China,” Central South University, vol.14,pp.307-311,2013. 